\title{
4. IGUALDAD Y DISCRIMINACIÓN SEXUAL EN LA JURISPRUDENCIA DEL TC
}

MARÍA LUISA BALAGUER CALLEJÓN

Profesora de Derecho Constitucional Universidad de Málaga 


\section{SUMARIO}

1. INTRODUCCION. LA IGUALDAD EN EL ORDENAMIENTO CONSTITUCIONAL. DiFERENTES POSICIONES DE LA IGUALDAD.-II. LA CONSTITUCIÓN ESPAÑOLA Y LA IGUALDAD SEXUAL.-III. LA JURISPRUDENCIA DEL TRIBUNAL CONSTITUCIONAL EN MATERIA DE DISCRIMINACION SEXUAL: a) Igualdad sexual y valores constitucionales (Estado Social de Derecho). b) Elementos que constituyen el juicio sobre la discriminación: racionalidad y razonabilidad. Los tests de proporcionalidad, arbitrariedad y justificación. El tertium comparationis. c) La prueba. IV. CONGLUSIONES. 
Revista de Derecho Politico, núm. 33, 1991, pp. 99-123

\title{
4. IGUALDAD Y DISCRIMINACIÓN SEXUAL EN LA JURISPRUDENCIA DEL TC
}

\author{
POR \\ MARÍA LUISA BALAGUER CALLEJÓN \\ Profesora de Derecho Constitucional \\ Universidad de Málaga
}

\begin{abstract}
I. INTRODUCCIÓN. LA IGUALDAD EN EL ORDENAMIENTO CONSTITUCIONAL. DIFERENTES POSICIONES DE LA IGUALDAD
\end{abstract}

Aunque tendemos a considerar la igualdad principalmente como un derecho constitucional, de forma similar a la libertad, es además un valor superior que tamiza todo el ordenamiento constitucional. La igualdad también, es un principio general del derecho, reconocido constitucionalmente, con lo que el artículo 14, donde se residencia la igualdad como derecho público subjetivo, no es, sin embargo, más que un aspecto de todos aquellos que recoge el texto constitucional.

Repasando la Constitución, podemos llegar a sistematizar todos estos aspectos en la igualdad:

En primer lugar, el artículo 1.1 empieza hablando de la igualdad, en cuanto valor superior, junto a la libertad, la justicia y el pluralismo político. Teniendo en cuenta que se sitúa la igualdad junto a valores que son la máxima expresión de un Estado de Derecho, es evidente que el constituyente considera a la igualdad como un presupuesto también de la forma de convivencia social que se diseña en el texto constitucional.

Antes de llegar al artículo 14, que formalmente prohíbe la discriminación, hemos de encontrar todavía una igualdad material, contenida en el artículo 9.2, que probablemente sea la norma más importante que contiene el texto constitucional de cara a las posibilidades de cambio social. Aquí la igualdad se sitúa nuevamente al mismo nivel de la libertad, y se exige el concurso de todos los poderes públicos para la consecución de la 
igualdad real. El término «remover», es interpretado como la exigencia de una conducta que activamente se enfoque al cumplimiento de la igualdad.

Al llegar al artículo 14 encontramos ya una formulación de la igualdad que la doctrina viene considerando como «igualdad formal», en oposición a la «igualdad material», del artículo 9.2, y que consiste fundamentalmente en la igualdad ante la ley y la igualdad en la ley ${ }^{1}$.

Todavía hace falta apelar al artículo 24.1 para encontrar un nuevo criterio de igualdad, la igualdad en la aplicación de la ley. Lo que se podría denominar una «igualdad procesal», en el sentido de que se trata de la igualdad en el proceso de aplicación de la norma ${ }^{2}$. Aquí la doctrina del TC ha vacilado entre la aplicación del artículo 14 y la del $24{ }^{3}$.

\section{LA CONSTITUCIÓN ESPAÑOLA Y LA IGUALDAD SEXUAL}

Hasta aquí la igualdad que genéricamente impide toda forma de discriminación. Pero en relación con la mujer, hay todavía una serie de normas que, de forma directa o indirecta, van a tener como consecuencia una mayor igualdad social de la mujer.

Así, el artículo 32.1 cuando establece que «El hombre y la mujer tienen derecho a contraer matrimonio con plena igualdad jurídica», está sentando unas bases que permiten la configuración de aspectos sociales nuevos en las relaciones sociales. Aunque se trate de una afirmación hasta cierto punto innecesaria, por estar ya contenida la igualdad en el artículo 14 , no hay que olvidar, sin embargo, que el artículo 14 establece un

- Acerca de la igualdad ante la ley, ver E. Alonso García, «El principio de igualdad del artículo 14 de la Constitución española», en RAP, n. ${ }^{\circ} 101-02$. Sobre la igualdad en la ley, J. JIMÉNEZ CAMPO, "La igualdad juridica como límite al legislador», en REDC, $\mathrm{n} .^{\circ} 10$, Madrid 1983.

2 Cuando hablo de igualdad procesal, hago referencia a la igualdad desde un punto de vista de la tutela judicial, es decir, en tanto en cuanto, los órganos judiciales han de seguir sus propias resoluciones.

3 Efectivamente, M. JAEN VALLEJo puso de relieve la relación entre la igualdad ante la ley y la igualdad en la aplicación de la ley, que es precisamente la idea que se propone aquí de igualdad procesal, o igualdad en el proceso, que se residencia mejor en el artículo 24 de la Constitución que en el artículo 14, pensado para una igualdad como límite al legislador o a las actuaciones contrarias a la igualdad. La exposición de M. JAĖN, en El principio de igualdad en la aplicación de la ley por los órganos jurisdiccionales en la jurisprudencia del TC. Colegio de Abogados, Madrid 1987. 
criterio general, y el artículo 32.1 reafirma la igualdad en un tema en el que la mujer ha sufrido discriminación hasta un periodo muy reciente, en una histórica supeditación patrimonial al hombre. Por otra parte, al tratar el artículo 14 la igualdad de forma genérica, el desarrollo constitucional de la igualdad va a ser fundamentalmente jurisprudencial, por lo que, como veremos, el criterio de razonabilidad va a mediatizar en gran medida este desarrollo de modo que de no existir este claro pronunciamiento, habrían sido posibles algunas interpretaciones judiciales restrictivas.

Algo parecido viene a ocurrir con el artículo 39, por el que se igualan los hijos legítimos a los ilegítimos. El artículo 39.2 de la CE dice: «Los poderes públicos aseguran la protección integral de los hijos, iguales éstos ante la ley, con independencia de su filiación, y de las madres, cualquiera que sea su estado civil. La ley posibilitará la investigación de la paternidad". Son artículos, que aun cuando no establecen de una manera directa la igualdad sexual, pero tienen unas consecuencias muy importantes, por cuanto que desde la discriminación en la afiliación, se provoca un cierto rechazo social, que no sufre el padre, sino la madre, que se encuentra por lo general desamparada socialmente. Con la igualación en la filiación esto se solventa, y se sientan bases para una aceptación social de estas situaciones.

Y por último, el artículo 15 del texto constitucional, cuando regula el derecho a la vida, y a la integridad fisica y moral, abre la posibilidad de una vieja reivindicación feminista: El derecho de la mujer a su propio cuerpo ${ }^{4}$. Es un hecho obvio que la mujer tiene unas condiciones biológicas diferentes a las del hombre. E igualmente obvio es el dato de que es el hombre el que ha configurado la Historia, y el que ha asumido el protagonismo de la vida social. Las condiciones de producción y la actividad social y laboral se han convertido en condiciones naturales a la fuerza de ser hechos culturales repetidos. De ahi ha surgido siempre la oposición a la incorporación de la mujer al mundo social, bajo el aparente hecho natural de que la biología de la mujer se contradecía con las condiciones materiales de la producción, fundamentalmente por la necesidad de atender a la maternidad y por la inferioridad física para hacer frente a determinadas tareas sociales. En lugar de adaptar la producción y las estructuras a la naturaleza,

4 La Ley de Despenalización de determinados supuestos de interrupción voluntaria del embarazo, cuando fue sometida a recurso previo de inconstitucionalidad, fue analizada por el TC con base a criterios de ponderación de valores, entendiéndose como valores en conflicto la vida de la madre y la vida del feto, la dignidad de la madre en relación al feto, etc., de manera que la dignidad de la mujer llegó a constituir el argumento a favor de la constitucionalidad de la mayor parte del proyecto de ley. Otras leyes que desarrollan aspectos indirectos de la igualdad sexual son la Ley $3 / 1989$, de 3 de marzo, de ampliación del permiso de maternidad, y algunas otras de penalización de prestaciones por hijos en divorcios con cónyuge culpable, etc. 
se pretendió así adaptar la naturaleza de la mujer a las estructuras, en una clara inversión del proceso. Así ha seguido planteándose el texto constitucional, y a ello obedece la legislación de desarrollo de la igualdad sexual, en materia laboral (ampliación del permiso por maternidad, permisos de lactancia y otras), entre otras razones, porque àdaptar a la mujer a la sociedad actual era posible, pero la idea de una sociedad configurada sobre otras bases, no lo era. LUCAS VERDÚ ha llamado la atención acerca del hecho de que exista una «subestimación jurídico-política de la condición femenina», que viene determinada por la atribución de una serie de elementos genuinamente femeninos que sirven de base a la creación de un estereotipo al que luego hacer incompatible con ciertas funciones públicas. Así, la atribución de una mayor sensibilidad, imaginación, capacidad de sufrimiento, predisposición a las virtudes hogareñas ${ }^{5}$, de modo que se enfoca a la mujer hacia estas actividades, que a la fuerza de ser culturales acaban siendo «naturales».

De alguna manera, aunque no se explicite en el texto, lo que parece pretender la CE es superar esta visión masculina de la sociedad e ir a una visión totalizante de la mujer y del hombre como dos aspectos de una Humanidad entendida como la suma de los dos sexos.

El planteamiento que la Constitución hace de la igualdad sexual y, por lo tanto, de la equiparación de la mujer al hombre (puesto que no cabe hablar de marginación histórica del hombre como sexo) ${ }^{6}$, presenta sin embargo algunas contradicciones importantes y algunas insuficiencias de interés.

Como contradicción importante, la Constitución ha caído en lo que la doctrina alemana ha llamado normas constitucionales inconstitucionales, en el artículo 57.1, cuando establece la preferencia del varón a la mujer en el orden sucesorio español de la monarquía. Pilar MELLADO y Yolanda GÓMEZ SÁNCHEZ, que han estudiado el tema de la posible inconstitucionalidad de esta norma constitucional, consideran que se vulnera el principio de igualdad en el seno de la propia familia real, al vedar a las infantas la

5 P. LUCAS VERDÚ, “El valor constitucional de la igualdad y la condición femenina», en Rev. de Política Comparada, núm. 7, 1981-82, "Entre los elementos que configuran la condición femenina y producen su subestimación jurídico-política hay que enumerar ante todo los elementos psicofísicos. En efecto, suele atribuirse a las mujeres una mayor sensibilidad, más imaginación y capacidad de sufrimiento, mayor religiosidad y predisposición a las virtudes hogareñas y al cuidado de los niños", pág. 33.

- Naturalmente lo que la Constitución no puede pretender es que la igualdad sexual supere los aspectos biológicos, pero sí es perfectamente posible, partiendo de las diferencias biológicas, ordenar la producción social conforme a estos elementos. 
posibilidad de acceder al trono con prioridad a su hermano de menor edad $^{7}$.

En lo que se refiere a las insuficiencias, la Constitución pretende, como dice LASARTE, que la discriminación entre los sexos, que está basada en la adaptación cultural de unas diferencias que no se integraron conforme a la igualdad, sino conforme al predominio de un sexo sobre el otro, se puedan corregir de forma que las diferencias no hagan jerarquizables los sexos, sino solamente diferentes ${ }^{8}$.

Esta igualación podia haberse hecho de diferentes formas. Después de la publicación de la Constitución, y por mandato de ésta, podía haberse promulgado una ley por la que se hubieran tratado en bloque todos los temas relacionados con la igualdad de la mujer. El constituyente no vio eso y dejó planteada la igualdad como un derecho subjetivo que admitía el ejercicio de una acción procesal individual que permite acudir a los tribunales en demanda del derecho. Con ello se reduce a nivel individual un problema que es colectivo y cuya solución debió buscarse de forma colectiva en aras de la efectividad. LUCAS VERDÚ planteó la posibilidad de un ejercicio en bloque de estos derechos, que habría permitido a las mujeres la restauración de una situación de nivelación de desigualdad histórica, y que se podía haber articulado con la inclusión de una norma de modo tal que incluida en el capitulo III del Título que regula los Derechos Fundamentales, y comoquiera «que contemplase la específica situación de la situación femenina serviria para que el legislador, el juez y la Administración adoptasen las medidas pendientes en bloque, de una sola vez, orientadas a suprimir los condicionamientos femeninos en el plano jurídico, económico-social y cultural, sin que cada mujer tuviese que verse obligada a recurrir, en el caso que particularmente les afecte, ante los tribunales» ${ }^{9}$. Esta transformación en bloque no se pensó, y las competencias en materia de igualdad de la mujer están teniendo su desarrollo constitucional en el ámbito legislativo con la publicación de normas tendentes a la consecución de la igualdad, en el Ejecutivo con la creación de un Instituto de la Mujer, dependiente del Ministerio de Asuntos Sociales ${ }^{10}$, y en lo Judicial con una línea jurisprudencial más o menos vacilante en torno a la igualdad.

7 Pilar Mellado y Yolanda Gomez SANCHEZ, "En torno a la posible inconstitucionalidad del apartado primero del artículo 57 de la Constitución Española de 1978", La Ley, vol. 4, 1984.

* J. LASARTE, «La equiparación entre hombre y mujer en la Constitución». La Ley. 648. 1983.

9 Lucas Verdú, op. cit., pág. 40.

to El Instituto de la Mujer creó el Plan de la lgualdad para la Mujer, asumido luego por el Ministerio de Asuntos Sociales, que conlleva el compromiso en Consejo de Ministros de la modificación de medidas legislativas por parte de cada uno de los Ministerios, en sus competencias correspondientes, para la consecución de la igualdad de la mujer. 


\section{LA JURISPRUDENCIA DEL TRIBUNAL CONSTITUCIONAL EN MATERIA DE DISCRIMINACIÓN SEXUAL}

\section{a) Igualdad sexual y valores constitucionales (Estado social de Derecho)}

Es precisamente esta línea jurisprudencial la que vamos a estudiar en función de los criterios que viene siguiendo el TC en materia de igualdad y discriminación. Si hemos iniciado nuestra exposición siguiendo la idea de que en realidad lo que viene a hacer la Constitución en materia de igualdad sexual es intentar corregir una desigualdad histórica de las mujeres en relación a los hombres, lo primero que se detecta como contradicción básica en el desarrollo de la jurisprudencia del artículo 14 es que el TC no capta inicialmente en sus sentencias esta línea constitucional, partiendo de que la igualdad sexual, en lugar de ser un error histórico a corregir, es una realidad actual a mantener. $Y$ puesto que existe el derecho a la igualdad sexual, no caben ni las discriminaciones de la mujer respecto del hombre ni las discriminaciones del hombre respecto de la mujer, imponiéndose un criterio de igualdad en ambos casos. Coincide esta línea jurisprudencial con un hecho significativo, y es que las postulaciones procesales se inician por parte de varones que se consideran discriminados en el ámbito laboral respecto de sus compañeras, a consecuencia de unos residuos proteccionistas de la legislación laboral franquista en materia de trabajo nocturnos de mujeres, reducción de jornadas, mayor cobertura de seguridad social, y otros análogos. Esto inicia la línea jurisprudencial de conectar la igualdad a otros valores constitucionales. $Y$ aquí es donde a mi modo de ver se produce una identificación poco correcta entre los valores constitucionales y la igualdad. La sentencia que inicia este contacto entre la igualdad y los valores superiores de la Constitución es la 103/83, de 22 de noviembre, que conoce sobre la cuestión de inconstitucionalidad planteada sobre el artículo 160 de la Ley General de la Seguridad Social, y por la que se declara inconstitucional el párrafo segundo del artículo 160 de la Ley, y el inciso del párrafo $1 .^{\circ}$ de este artículo, que dice "la viuda".

La sentencia estima la cuestión de constitucionalidad sobre la base de que la igualdad sexual es un hecho actual, no existen desigualdades históricas previas que justifiquen un trato de favor a la mujer, y por consiguiente hay que nivelar la ley para propender a esta igualdad. La escasa consideración que hace el fundamento jurídico de la sentencia $n .{ }^{\circ} 6$ acerca de la situación histórica de la mujer le lleva a considerar que no debe tomar en cuenta este argumento, por ser precisamente contrario a lo que el mismo artículo 14 preconiza.

El voto particular formulado por el magistrado don Francisco Rubio Llorente se aleja considerablemente del sentido de la sentencia, para apro- 
ximarse de lleno a los valores constitucionales en los que se ha definido este artículo 14. Partiendo de la base de que «es un hecho notorio que en nuestra sociedad se diferencian muy nítidamente las funciones que en el seno de la familia corresponden a hombre y mujer. La división doméstica del trabajo arroja sobre ella la parte más importante, cuando no la totalidad, del trabajo del hogar y dificulta su incorporación al mundo de la producción, en el que generalmente desempeña tareas peor retribuidas que las que asumen los hombres, siendo iguales las circunstancias restantes». De este modo se conecta con el campo de valor en el que el constituyente ha definido la igualdad sexual del artículo 14, puesto que ignorar estas circunstancias es partir de una situación que no es real. El voto discrepante entiende que habria de derogarse con el tiempo esta discriminación, pero sería una situación a considerar cuando la desigualdad se fuera nivelando.

\section{b) Elementos que constituyen el juicio sobre la discriminación. Racionalidad y razonabilidad. Los tests de proporcionalidad, arbitrariedad y justificación. El tertium comparationis}

Como ya ha estudiado C. FERNÁNDEZ-MIRANDA CAMPOAMOR, hay una clara distinción por parte del TC entre las sentencias en las que ha de estimarse inconstitucionalidad de la norma y aquellas que juzgan actos de la Administración o de los órganos jurisdiccionales de.cara a determinar si ha existido discriminación. En el primer caso son más amplias y generosas las interpretaciones, y en el segundo caso se complica un elemento que es el onus probandi ${ }^{11}$, acerca del cual el TC no acaba de crear criterios estables en el derecho a la igualdad, pues si bien en algunas sentencias parece exigir la carga de la prueba al que alega el derecho (doctrina clásica del derecho procesal), en otras mantiene la relación entre la carga de la prueba y la tutela judicial, de modo que reparte la carga de la prueba al objeto de no provocar indefensión

En el TC ha habido una linea inicial de defensa de la igualdad, al margen de los criterios sociales envolventes. Así, la defensa de la igualdad, ampliando privilegios de la legislación anterior proteccionista de la mujer, al hombre en dos casos concretos, el de la equiparación a la jornada nocturna de ATS masculinos y femeninos y la pensión de viudedad.

Luego, hay una inflexión que yo creo que es correcta desde el punto de vista del artículo 14, aunque pueda ser discutible desde el punto de vista laboral, que es el de considerar como hace despues en la ST 128/87, de 16

\footnotetext{
C. Fernández-Miranda Campoamor, «La discriminación por razón de sexo», en RDP, 1988, pág. 122.
} 
de julio, por la que se deniega la prestación de ayuda a guarderias, en la que da un giro total a la doctrina y empiezan a triunfar las tesis de los votos particulares formulados en las primeras sentencias.

Al primer período corresponde la Sentencia 81/1982, de 21 de diciembre, acerca del carácter democrático del Estado de Derecho, por el que «dado el carácter social y democrático del Estado de Derecho que nuestra Constitución erige y la obligación que al Estado impone los artículos 9.2 y 35 de la CE, de promover las condiciones reales y efectivas y la promoción a través del trabajo, sin que en ningún caso pueda hacerse discriminación por razón del sexo, debe entenderse que no se puede privar al trabajador de las conquistas sociales conseguidas. De esta manera no puede restablecerse la igualdad privando al personal femenino de los beneficios que en el pasado hubiera adquirido, sino otorgando los mismos derechos al personal masculino que realiza idénticos trabajos y actividad personal...". Aunque veremos después el giro de la jurisprudencia del TC en este sentido, no deja de ser llamativo el intento del TC de cruzar dos tipos de desigualdad: la especifica de la discriminación sexual con la indeterminada de la clase social.

En ambos períodos, sin embargo, la doctrina del TC descansa sobre los mismos criterios técnicos de interpretación:

- Hay discriminación si ante supuestos de hecho iguales se aplican normas distintas.

- Hay discriminación si la diferencia de trato (entiéndase éste jurídico y de hecho) no está justificada.

- Hay discriminación cuando el órgano jurisdiccional no justifica su cambio de criterio.

En sintesis, como ha puesto de relieve ALONSO GARCÍA, hay discriminación cuando no se resiste la racionalidad ${ }^{12}$. La racionalidad y la razonabilidad se convierten en el eje de la discriminación y, por lo tanto, cuando esta racionalidad se supera no hay discriminación.

Ello ha creado una serie de variaciones en torno a la racionalidad como test que se complementa con otra serie de tests que contemplan aspectos parciales de este juicio discrecional en torno a la igualdad y a la determinación de si existe o no discriminación ${ }^{13}$. Si nosotros vemos la apli-

12 Alonso Garcia, E., "La persecución de fines constitucionales ilegitimos conlleva automáticamente la irracionalidad de la desigualdad», op. cit., pág. 49.

${ }^{13}$ Ibidem, pág. 23 y ss. 
cación práctica de estos criterios, la consecuencia es de todo punto lógica: de la ilegalidad no puede desprenderse la igualdad, pues no hay juicio de racionalidad en la contemplación de la arbitrariedad (ST 43/82, de 6 de julio, y otras posteriores).

La racionalidad, entendida en el doble sentido de racionalidad y razonabilidad, vienen a ser una misma cosa. La racionalidad es la adecuación medios-fines. Pese a su aparente objetividad, este test es el mismo que el de razonabilidad ${ }^{14}$. El test de la razonabilidad, como dice ALONSO GARCIA, consiste en la exigencia de que la distinción de trato carezca de una justificación objetiva y razonable.

La constituye la exigencia del límite de edad, cuando se justifica por la complejidad del cargo en función de la capacidad que no se le supone al mayor de sesenta años, o la permanencia que evite que constantemente se tenga que cubrir la plaza (ST 75/83, de 3 de agosto ). Ahora bien, aunque la doctrina y el TC utilicen los términos de racionalidad y razonabilidad de forma equivalente, no son exactamente iguales, ni llevan necesariamente a las mismas consecuencias.

La racionalidad entendida como «la decisión juridica suceptible de ser justificada racionalmente" ${ }^{15}$, por oposición a la razonabilidad, que "operaría como un criterio o límite general del ordenamiento juridico" ${ }^{16}$. La razonabilidad sería el aspecto práctico de la racionalidad, por oposición al aspecto lógico o deductivo, que representaria la racionalidad. Opera la razonabilidad con carácter subsidiario de la racionalidad ${ }^{17}$. Por ello, cuando una norma aparentemente carece de racionalidad es oscura, no se ve claramente su intención, ha de ser interpretada con criterios razonables, de racionalidad. Se convierte la razonabilidad en un criterio interpretativo, de modo que la norma se aplica con una lógica hermenéutica.

ALONSO GARCIAA, por su parte, estima que el juicio de racionalidad $y$ el de razonabilidad no difieren en absoluto, y lo hace en base a criterios que podemos desprender de los fines, de la relación medios-fines a que atienden ambas cuestiones. De una parte, porque aunque a primera vista el test de la racionalidad lo que viene a buscar son los criterios en los que se basa la norma, desde un punto de vista de la relación medios-fines, lo que exige plantearse, por lo tanto, son los fines de la norma, su justificación, en suma, es decir, lo que la norma pretende cuando se crea, y por consiguiente, desde un punto de vista constitucional, lo que se pretende es la formulación en la norma de los fines constitucionales perseguidos, que el

Alonso García, E., «La persecución de fines...», pág. 47.

M. AtIEnZA, «Sobre lo razonable en el derecho», REDC, 1989, pág. 47.

Ibidem, pág. 95.

lbidem, pág. 96. 
TC tiene que captar para realizar su labor interpretativa. Lo que desde un punto de vista de la razonabilidad se pretende es hallar la razón de ser de la norma, esto es, la justificación. Hay una confusión entre el fin perseguido por la norma y la justificación de la causa por la que esta norma se crea. EI TC también identifica el concepto de razonabilidad con el de racionalidad, la causa con el fin; sin embargo, son cuestiones distintas, pues aun cuando ambas están inmersas en campos valorativos (y quizá es en este sentido en el que ALONSO GARCÍA los homologa ${ }^{18}$, sin embargo, no necesariamente estos campos valorativos coinciden en cuanto a la razón de ser y el fin. Dicho de otra forma, la razón de ser del artículo 14, en cuanto al sexo, está en que la mujer ha sido discriminada en el orden social, laboral, político, económico, en definitiva, que hay un trato histórico discriminatorio en la mujer. Pero el fin del artículo 14 parece ser tendencialmente la igualdad. Ambas cuestiones están presentes en la norma, pero no se manifiestan de la misma forma. $Y$ desde luego el fin de la norma, entendiendo por fin su tendencia, su finalidad, lo que esencialmente persigue, no se puede identificar con la razón de ser de la norma, que apunta a la causa, al origen. No debe confundirse el origen con el fin, pues en el origen de la norma está su nacimiento; en la finalidad, está aquello que se pretende conseguir. De esta forma, cuando el constituyente se plantea la razón de ser de la discriminación redacta el artículo 14 para conseguir la igualación de ciertos niveles, dentro de lo que son las formas de vida europeas, con ciertos desniveles sociales, es decir, de acuerdo con los criterios de igualdad dominantes en los países del entorno el constituyente crea una norma para nivelar ciertas desigualdades derivadas de algunas circunstancias especificas. Por ejemplo, el sexo como factor de desigualdad. La razonabilidad de la norma, por así decirlo, su justificación, está en la desigualdad existente. Pero su racionalidad, es decir, el fin que pretende la ley está en la igualación de los sexos. Sin embargo, en este caso, la racionalidad, finigualdad objetiva, lógica y racional, no se corresponde con la razonabilidad, con la justificación de esta norma, que desde que nace, según consta en las mismas deliberaciones de las Cortes Constituyentes, porque hay una desigualdad, y la razón de ser de crear esta igualdad sexual, estaba justificada por la inferioridad de trato de la mujer respecto al hombre. El artículo 14 no se pensó inicialmente para construir una igualdad del hombre, que tenía una consideración jurídico-positiva superior y prepotente, hasta la promulgación de la CE, sino precisamente para crear las condiciones para que la mujer pudiera llegar a ser igual que el hombre. Luego, la razón de ser no estaba en una igualdad objetiva sino en una desigualdad preexistente. Ahora bien, lo que ocurre es que una vez que el articulo 14 se incorpora al texto constitucional, ya tenemos una norma que desde el punto de vista objetivo establece la igualdad genérica. $Y$ de este modo cuantas 
veces se alegue por los hombres la igualdad, si se sienten discriminados respecto de la mujer, se habrá de estimar este derecho, si en lugar de utilizar el criterio de la razonabilidad (razón de ser del art. 14) se utiliza el de la racionalidad (fin de cumplimiento de la igualdad). $Y$ así es precisamente cómo se inicia la jurisprudencia del TC en esta materia. Cuando el TC resuelve la cuestión de inconstitucionalidad en la ST 103/83 mencionada, equiparando el viudo a la viuda a efectos de pensión como cónyuge supérstite, lo que hace es utilizar el criterio de la racionalidad de la norma y no el de la razonabilidad. Por esta razón el TC llega en su mayoria a la estimación de la cuestión de inconstitucionalidad. Y el segundo voto disidente llega a la conclusión contraria, justamente en base al criterio de la razonabilidad, puesto que lo que se plantea no es la igualdad como fin sino la desigualdad en su origen.

Por esto cabe decir con más exactitud que no son la misma cosa la racionalidad que la razonabilidad, pues las conclusiones a que se pueden llegar en la actividad interpretativa de la norma no son exactamente las mismas.

Dicho esto, conviene aclarar también que el juicio de racionalidad con el que el TC comienza operando, pese a plantearse desde una óptica racionalista, mantiene sin embargo contenidos de valor, si bien no son los mismos obviamente que aquellos a los que le conduce posteriormente el juicio de la razonabilidad. Y esta vertiente valorativa en ambos casos, no deviene de que el razonamiento acerca de la discriminación se realice con una tendencia finalista o no, sino de la pura técnica interpretativa del TC que desde sus inicios se sitúa en torno a la jurisprudencia de valores en lugar de moverse en torno a la jurisprudencia de intereses. La interpretación del Derecho en ausencia de valores constitucionales, como ha sido nuestro ordenamiento hasta fechas recientes, puede moverse con mayor o menor comodidad en cuanto a una jurisprudencia de los intereses en conflicto, pero desde luego, en una Constitución normativa, es obligado acudir a la jurisprudencia de valores, pues sólo aquí se puede interpretar el derecho "conforme a la Constitución". Lo contrario daria lugar a una aplicación judicial desligada de la norma fundamental. Por ello, el juicio que el TC realiza, aunque se afirme constantemente que es un juicio objetivo, sin embargo, sólo puede serlo dentro del campo valorativo que la Constitución impone, y los resultados de este juicio no son objetivos, sino que quedan perfectamente lineados dentro de los fines constitucionales. Hay un argumento previo y es el determinar hasta qué punto igualdad y racionalidad no son conceptos hasta incompatibles, o dicho de otra forma, hasta qué punto la igualdad no debe trascender los límites de la racionalidad para ir al verdadero campo valorativo sin que necesariamente haya de estar hipotecado por la racionalidad. Cuando el TC dice que la igualdad ha de ser razonable y justificada entramos en el campo de querer racionalizar cuestiones que no son demasiado razonables, teniendo que acudir a criterios que a menudo no son demasiados objetivos, y que el propio TC se 
ve obligado a objetivizar, creando categorias que a menudo no responden a la objetividad.

El juicio de racionalidad o razonabilidad es insuficiente de cara a satisfacer la discriminación. Si el TC se sitúa ante la perspectiva de tener que conseguir la igualdad sexual en el campo de la razonabilidad y estima discriminación solamente cuando la diferencia de trato no es objetiva y razonable, es decir, en el campo de la justificación, es posible que en casos de plena justificación de la teoría de la razonabilidad estemos ante casos discriminatorios que, sin embargo, sean capaces de superar sin problemas el test de la desigualdad. Las mismas discriminaciones positivas están completamente fuera de la aplicación del test de la razonabilidad para situarse en otro campo de la justicia social.

Por otra parte, el hecho de que la razonabilidad sirva de fundamento a la desigualdad conforme a criterios de valor generalmente aceptados, pone en conexión la actividad del TC en su precisa dimensión social. Es el caso del auto 446/84, por el que el TC desestima el recurso de amparo presentado por un militar condenado por abusos deshonestos, en amparo de igualdad, por discriminación del artículo 352 del Código de Justicia Militar que castiga al militar que cometa abusos deshonestos con persona del mismo sexo, sin considerar delito los mismos actos cometidos con persona de diferente sexo. EI TC no estima la demanda por entender que el tertium comparationis no ofrece supuestos de hecho idénticos, ya que los actos de igual naturaleza cometidos con personas de sexo diferente y los cometidos de forma homosexual no se pueden comparar: «No compara en abstracto situaciones iguales, pues los actos deshonestos tipificados, realizados entre individuos del propio sexo, han de referirse como parece obligado a las relaciones homosexuales, que tanto por los sujetos que las cometen como por su mismo contenido y finalidad no son asimilables ni comparables con las relaciones heterosexuales» (FJ n. $\left.{ }^{\circ} 6\right)$. ¿En qué se basa esta distinción que hace el TC? En dos argumentos fundamentales, que aclara en el FJ 5: «En el caso de existir diferentes supuestos de hecho es aceptable la desigualdad si resulta razonable y fundada, de acuerdo con criterios de valor y juicio apoyados con generalidad, por producirse una lógica conexión de proporcionalidad entre los medios y el fin perseguido".

$Y$ un segundo elemento: los valores jurídicos militares, entre ellos, la condición militar, "como particular manera de ser y actuar en pro de altos fines, que comporta la sujeción a un sistema normativo en que se imponen de forma muy significativa determinados valores, que no permiten su lesión sin originar un sensible desvalor, cual sucede con el honor profesional e inmaterial de una institución como la militar».

En el caso de que el TC hubiera utilizado el juicio de racionalidad en lugar de razonabilidad, hubiera sido posible estimar el recurso de amparo, pues la primera parte del razonamiento del TC es impecable: El FJ 4 del auto, decía que la igualdad es el derecho subjetivo a recibir un tra- 
tamiento idéntico. Que este tratamiento en supuestos de hecho idénticos no exige prueba alguna, salvo la de la propia identidad. «Pero que cuando son diferentes los supuestos de hecho hay que entrar en la comprobación de que sea razonable y fundada la desigualdad conforme a criterios de valor. $Y$ es justo aquí donde ya no debe avanzarse. Si los supuestos de hecho son una conducta sexual en ambos casos, la ponderación que el Tribunal realiza ofrece múltiples soluciones: que sea conducta sexual libre, en cuyo caso es el artículo $15 \mathrm{y}$ el derecho al propio cuerpo el que puede primar como factor de ponderación. Que se trate de relaciones basadas en dependencia jerárquica, que pudieran generar un acoso sexual, etc., pero existiendo referencias a valores constitucionales, como son en primer lugar la libertad, y en segundo lugar el derecho al propio cuerpo, acudir a criterios sociales es discutible, máxime cuando se mantienen juicios de valor como el de que las relaciones heterosexuales tienen distinto "contenido y finalidad" que las que no lo son.

La racionalidad en si, aun cuando pueda ser operativa, es por esta misma razón perfectamente instrumentable. El mismo argumento que sirvió al TC para estimar inconstitucional la norma que obligaba a la jubilación a determinada edad, pudo servir para su desestimación, pues si bien es correcto el factor empleo, no es menos correcto estimar otro factor, por ejemplo, el rendimiento. ¿Por qué pensó el TC que la jubilación anticipada obedecía sólo a razones de fomento de empleo joven y no a mejoras de rendimiento? $Y$ este argumento le habría llevado a valorar de forma diferente la pretendida justificación, pues el joven rinde más. $U$ otro argumento, el considerar aspectos diferentes de la ley la valoración de que la distribución del escaso empleo había de hacerse empleando mano de obra joven, de cara al rendimiento o de cara a ocupar sectores de riesgo de drogadicción, en relación con sectores menos productivos y de menor riesgo social en su desempleo. O sea, que cualquier razonamiento que se quiera hacer es perfectamente válido desde una óptica que depende de qué valores se tomen como predominantes.

La idea de que la desigualdad tiene que tener un fin que sea compatible con los valores constitucionales, es algo que se resbala a poco que profundicemos en ella, pues desde luego que cualquiera que sea el fin pretendido por la norma, según la lectura que se haga de ella, podemos encontrar con que sea más o menos compatible.

La proporcionalidad, la idoneidad, son cuestiones que llevan un fondo de subjetivismo evidente. Una cosa es proporcionada a otra, según entendamos que lo es o que no lo es, pero en esto hay valoraciones implícitas.

Por ello, puede entenderse que la racionalidad como elemento de distinción de la discriminación depende de una serie de criterios valorativos como van a ser: 
1. Los criterios que tenga el mismo Alto Tribunal acerca de la CE, entendiendo por ello los fines que la Constitución ha formulado y a los que tendencialmente se supone que debe orientarse.

2. De los criterios que le merezcan a su vez tanto los supuestos de hecho como los que se le ofrecen como tertium comparationis.

3. De cómo se establezcan las relaciones entre el supuesto de hecho y las consecuencias jurídicas, de cara a determinar si la conducta o en su caso la norma superan los tests establecidos como parámetros de proporcionalidad, arbitrariedad e identidad. En el primer caso, se trata de ver cómo el artículo 14 se relaciona con otros artículos de la CE incluso con una concepción global de la sociedad y de la igualdad misma. En tal sentido el TC hace, en relación con los valores constitucionales, constantes pronunciamientos no sólo en los fallos, sino que las disidencias de los votos particulares se mueven constantemente en este entorno. Más que derivadas de cuestiones técnicas, que ocurren en sentencias relacionadas con otros derechos fundamentales, en la igualdad de las diferencias de criterio acerca del fallo expresadas en los votos particulares, suelen hacer referencias a contenidos de valor acerca de la desigualdad misma y la racionalidad o no de la conducta o norma discriminatorias.

En segundo lugar, la racionalidad va a depender igualmente de cómo se valore el supuesto de hecho objeto del amparo. Si este supuesto de hecho se estima que presenta identidad, similitud o diferencia justificada, es algo que depende de las valoraciones que el tribunal tenga acerca de qué tipo de categorías son comparables y homologables, y aquellas que no lo son. EI TC ha entendido en el auto $446 / 84$ que la conducta heterosexual y la homosexual no son homologables, pero, como vimos al analizar este auto, posiblemente porque en el ámbito castrense estas diferencias adquieran diferente significación. ¿Quiere esto decir que el TC en diferentes circunstancias habría estimado iguales u homologables los supuestos de hecho? Probablemente, sí, porque lo que pretende el TC es captar el campo valorativo en el que se desarrollan los supuestos de hecho, y por tanto, el colectivo al que se dirige la sentencia.

$Y$ en tercer lugar, decíamos que la racionalidad también va a depender de cómo se establezcan las relaciones entre los dos términos de la comparación presentados y las consecuencias jurídicas que entienda el TC que se desprenden de esa conducta o norma que trata de forma desigual dos cuestiones aparentemente iguales. Es decir, de cómo se articule la argumentación en torno a las consecuencias jurídicas de la desigualdad, si es o no relevante esta desigualdad. (Test de la relevancia, en definitiva). $\mathrm{Si}$ entendemos que hay dos supuestos de hecho iguales, pero que la diferencia de trato está justificada, no hay discriminación, pero la valoración 
en la diferencia de trato significa nuevamente valorar por parte del TC qué diferencias son justas y cuáles no, para concluir en un juicio de valor acerca de si es acorde con la Constitución tal modo de actuar. Es en este momento del proceso lógico cuando verdaderamente tiene lugar la conexión entre los valores dominantes de la sociedad y los valores constitucionales, independientemente de los que el TC pueda además introducir en el proceso. En esta circunstancia, el juez constitucional debe ser el catalizador de todos estos valores para intentar armonizarlos. Aqui, además, puede darse el caso de que la sociedad sintonice o no con los valores constitucionales, y decidir el propio tribunal si ha de atender a unos o a otros, pero al resolver, necesariamente, ha de hacerlo en torno a ellos.

En el test de la proporcionalidad, lo que se trata de averiguar es si la diferencia o discriminación mantiene niveles tolerables o hay que decidir que el acto o la norma son discriminatorios. En realidad se trata de un elemento de la racionalidad o de la razonabilidad, en su caso, aunque estemos hablando de matices diferentes, pues el test de la proporcionalidad lo que viene a significar es el juicio de valor propiamente dicho. Vistos los supuestos de hecho, la ponderación se efectúa a través de este test de la proporcionalidad, es, por así decirlo, la tolerancia o la repugnancia de la conducta, la norma, en contraste con el artículo 14.

EI TC admite la proporcionalidad con un doble carácter: de una parte, como principio constitucional, y de la otra, como un principio general del derecho. La proporcionalidad obedece a la idea de que hay una necesidad de justicia, ayuda en tal sentido al TC al cumplimiento de la justicia material.

Se desenvuelve en torno a la relación medios-fines, es un concepto más estricto que el de la razonabilidad, puesto que sólo es esto, la medida en que se realiza o la adecuación.

La arbitrariedad o, lo que es igual, la falta de justificación, es lo que califica la discriminación. Hay discriminación cuando hay arbitrariedad. Por consiguiente, cuando se trata de analizar si hay o no discriminación, lo que se realiza es un juicio acerca de la arbitrariedad por lo que hay en el artículo 14 una interdicción de la arbitrariedad. La arbitrariedad es la falta de justificación objetiva y razonable ${ }^{19}$.

La justificación es la otra cara de la moneda de la arbitrariedad. La justificación es lo que impide la consideración de la arbitrariedad, que se trate de una conducta objetiva y razonable. Por lo tanto, de alguna forma son elementos que figuran como intercambiables en la estructura de los razonamientos del TC cuando se puede decir que no deberian serlo, pues si en realidad la razonabilidad es un poco el elemento fundamental, decir nuevamente que la arbitrariedad es ahora la falta de justificación «razonable» remite nuevamente a la «razonabilidad», dando vueltas en torno a

19 Sobre la discriminación puede consultarse, Miguel Rodríguez Piñero y M. F. Fernández López, Igualdad y discriminación. Edit. Tecnos, Madrid 1986. 
una serie de elementos que acaban perdiendo sustantividad. (Sentencia 67/ 82 , de 15 de noviembre, «el tratamiento legal desigual tiene como límite la arbitrariedad, causa de discriminación, es decir, la falta de una justificación objetiva y razonable».)

El término de comparación, por último, lo que se conoce como tertiums comparationis, es la exigencia al solicitante en amparo de que ofrezca al tribunal un término de comparación para aquellos casos en los que los supuestos de hecho no son idénticos, sino similares, $y$ hay que realizar la investigación de que hay una comparación que establecer en ellos. Este elemento, que sirve de comparación, plantea numerosos problemas de orden técnico. Así, el caso de la ST 100/88, de 7 de junio, por la que se desestima el amparo sobre igualdad, en base a que el término de comparación lo constituye una sentencia posterior en lugar de las sentencias anteriores, como si el tiempo fuera un elemento distorsionador de la naturaleza de la posible similitud. Las consecuencias de este entendimiento tan restrictivo del término de comparación ha llevado a veces al TC a confundir la igualdad con la identidad, exigiendo que los supuestos de hecho no fueran sólo comparables, sino iguales. Es la ST 109/88, que produce la desestimación del amparo interpuesto por cotizante al Régimen Especial de Servicio Doméstico, a quien se deniegan prestaciones por parentesco. La cotizante, sobrina de religiosa a quien cuida, pide amparo por discriminación establecida en pf. ${ }^{\circ} 2$, del artículo 3 del RD de 25 de septiembre de 1979, por el que se excluye a los sacerdotes célibes de la razón de parentesco en orden a la afiliación de personas a su servicio. La no inclusión de religiosas, a estos efectos, supondría una discriminación basada en el sexo del contratante en principio contraria al artículo 14 de la CE. El TC entiende que el contratante no supone término idóneo de comparación, sino que solamente la persona discriminada, porque «la genuina discriminación por razón de sexo, raza, religión u otras circunstancias personales, es aquella que se refiere a la persona discriminada como portadora de tales aspectos o condiciones, mientras que aquí no se trataría en ningún caso de una discriminación por razón de las condiciones personales del supuestamente discriminado, que es el empleado, sino de una discriminación atendida a las condiciones del empleador". Esta restricción en el término de comparación no tiene ninguna razón de ser, pues lo que se tienen que comparar son las situaciones en sí mismas, independientemente de como se generen, y en todo caso. Esta especie de falta de legitimación activa a que alude el tribunal, en el fondo no es óbice procesal ni sustantivo para estimar la discriminación, pues los hechos son pura y simplemente que los sacerdotes, en cuanto hombre, pueden mantener personal familiar a su servicio cotizando a la Seguridad Social, y las religiosas, en cuanto mujeres, no pueden tenerlo. EI TC ha debido distinguir aquí entre la discriminación directa y la indirecta, que la doctrina entiende como dos formas 
de discriminación, en donde la segunda no es ni mucho menos secundaria respecto de la primera, sino probablemente más importante ${ }^{20}$.

\section{c) La prueba}

A menudo se habla de la necesidad de invertir la carga de la prueba en los casos de discriminación. ALONSO GARCíA ha aludido a la necesidad de la inversión del onus probandi, como requisito de la restauración de la igualdad ${ }^{21}$. Creo que además de la necesidad de invertir la carga de la prueba en la discriminación, también es importante el tema desde el punto de vista de no provocar la indefensión. El artículo 24 de la CE es explícito cuando exige a los órganos jurisdiccionales que al juzgar no produzcan indefensión a las partes. Muy comúnmente, el discriminado está además en situación de indefensión cuando se le discrimina, pues suele estar en una posición de inferioridad social, étnica, etc., que le hace tener más dificultad de acceso a los medios materiales en general, que el que supuestamente realiza la actividad discriminatoria. Piénsese en la Administración en relación al particular, o en la empresa en relación al asalariado. No es razonable, ni por supuesto justo, que por no poder probar la verdad material el justiciable obtenga solamente una verdad formal, quedando sin reestablecer un derecho fundamental lesionado. En tal sentido, la doctrina tradicional del onus probandi incubit quid afirmat non quid negat, ha de verse mediatizada por un principio de defensa del orden constitucional, y por un principio superior del ordenamiento del cumplimiento del orden material de la justicia. Y por ello quizá es más acertado modificar la carga de la prueba de modo que sea exigible la prueba al que está en condiciones de probar. Es el sistema más justo de conseguir precisamente el principio de justicia material.

La primera sentencia en la que el TC se plantea el tema de la necesidad de distribuir la carga de la prueba es en la ST. 38/81, de 23 de noviembre, por la que se mediatiza la prueba en función de la búsqueda de la justicia material.

La sentencia 38/86, de 21 de marzo, entiende que la prueba incumbe al que alega, y que aunque de forma matizada, «el actor, como principal gestor de su propio derecho, está obligado a dirigir su actividad probatoria

20 Sobre discriminación directa e indirecta, M. C. ORTIZ LALLANA, «El principio de igualdad salarial y las discriminaciones indirectas por razón del sexo en el ordenamiento comunitario y en España», REDTrab., n. ${ }^{\circ} 29,1987$.

21 Alonso Garcia, E., op. cit., pág. 69. 
a demostrar la existencia real y efectiva de una diferenciación de trato vinculada a algún factor prohibido de diferenciación».

Con esto el TC da entrada de forma matizada a lo que aquí se expone, entendiendo que el artículo 14, al prohibir la discriminación, obliga en cierto modo a que se justifique la discriminación compatible con la idea de artículo 14, por lo que «el juzgador, ante una situación que pueda suponer razonablemente una discriminación de este tipo, no se limite a afirmar que no son suficientes las pruebas aportadas por el actor, sino que ha de exponer los motivos por los cuales entiende que no existe la aparente discriminación». Pero esa sentencia, que trata de analizar si existe discriminación en razón del sexo, considera que hay una obligación en el juez de velar porque no se perpetúen situaciones contrarias a la Constitución de manera que ha de poner su empeño en esto. Este principio se hace compatible con la exigencia de una diligencia al principal interesado en la prueba, que debe ser el solicitante del derecho. Por lo tanto se han de conjugar en orden a la prueba los siguientes factores, a mi juicio:

La necesidad de invertir totalmente la carga de la prueba cuando solamente pueda probar el que realiza la discriminación.

La necesidad del reparto de la carga de la prueba cuando lo que haya que probar sea posible de efectuar de una parte por el que postula y de otra por el que se opone.

La necesidad de que el actor sea diligente con la prueba.

La necesidad de que el propio juez sea vigilante con la prueba distribuyendo un poco de la carga de la prueba en función de quien esté en condiciones de efectuarla.

La importancia de esta sentencia radica fundamentalmente en el hecho de que el TC estima el amparo, no exactamente por el artículo 14 de la $C E$, sino más bien por una tutela jurídica, mandando retrotraer las actuaciones a la instancia para que se apure el terreno probatorio que ha sido insuficiente. El fundamento jurídico cuarto de la sentencia lo que viene a entender es que siendo posible que exista discriminación, porque además los indicios apuntan a ello, no es posible dejar de satisfacer el derecho, sin que se haya podido formar el juez criterio suficiente. Obliga al magistrado a dictar nueva sentencia por la que se valore de forma diferente la prueba $^{22}$.

${ }^{22}$ Nótese que, curiosamente, el TC devuelve los autos para que el juez dicte sentencia nuevamente valorando la prueba de forma distinta, pero al no ordenar que se practique nuevamente esta prueba, de alguna forma está condicionando al juez a que siga un determinado camino. 


\section{CONCLUSIONES}

Primera.-El carácter restrictivo de la interpretación del derecho fundamental a la igualdad por parte del TC.

Esto es especialmente visible en algunos aspectos procesales del procedimiento, como, por ejemplo, en la prescripción de la acción tendente a la reclamación del derecho.

Se ha afirmado que los Derechos Fundamentales son imprescriptibles por su propia esencia. Pero ello no obsta a que el TC haya situado el ejercicio de la acción procesal para reclamar el derecho en unas coordenadas temporales conforme a la prescripción de las acciones que rige en el orden jurisdiccional.

Una de las consecuencias fundamentales de esa determinada interpretación va a ser la prescripción de tres años que se estima en las acciones ejercitadas en el ámbito laboral conforme al juego de la entrada en vigor de la $C E$, en relación con la legislación laboral vigente en materia de contratos de trabajo (Decreto 17/77, de 4 de marzo, y la propia Ley de Contratos de Trabajo). Este criterio interpretativo es un tanto restrictivo, por cuanto que limita la aplicación del derecho a un plazo relativamente corto, en relación con el propio desarrollo constitucional que se preveía en los primeros años de jurisprudencia. Nada más entrar en vigor la LOTC, se accionaron en amparo las demandas contra la CTNE en solicitud de aplicación del derecho fundamental a la igualdad, pero la primera sentencia sobre el tema se produce el 14 de febrero de 1983 (ST 7/83), cuando está cerrada la acción para que todas aquellas trabajadoras excedentes que estuviesen a la expectativa del pronunciamiento del Alto Tribunal y que no pudieron interponer demanda por haberles prescrito la acción.

Esto dio pie a numerosas desestimaciones del TC de recursos de amparo por estar prescrita la acción, con lo que un problema formal imposibilitó el cumplimiento de la justicia material en unas condiciones en las que hasta cierto punto se pudo considerar interrumpida la prescripción (Auto 550/84, de 3 de octubre) ${ }^{23}$.

23 Sobre el tema, A. Figueruelo Burrieza, «Igualdad ante la ley, no discriminación por razón de sexo, "en $L a$ Ley, n. ${ }^{\circ} 843,1984$, en el que se ve cómo "si en lugar de basar la violación del derecho a la igualdad de las recurrentes en el artículo 14 de la Constitución, se hubiera hecho en el artículo 17 del ET, se estaria afirmando de forma tácita lo contrario de lo que hasta ahora se ha venido manteniendo, que los derechos fundamentales carecen de virtualidad plena en el texto constitucional y que ésta sólo se adquiere una vez que son desarrollados por una ley al efecto". 
El voto particular de DIEEZ-PICAZO proponia una solución más justa y más razonable jurídicamente de la que consiguió la mayoria. Hay una cuestión fundamental a esta argumentación, que no se explicita pero subyace en ella. A una desigualdad secular, es injusto conceder un plazo de tres años para intentar la igualdad. Sobre todo en cuando razona en el sentido de la dificultad de determinación del plazo en un derecho sometido a interpretación judicial, «un derecho cuya concreción sólo podía realizarse a través de un juego interpretativo no demasiado fácil, lo que equivale a echar a correr el plazo de prescripción cuando los titulares del derecho no tienen especial consciencia de serlo".

Por último, añadir que tampoco esa doctrina jurisprudencial es lineal. Con anterioridad el TC había matizado la prescripción en el sentido de que el cómputo del plazo para la prescripción de las acciones se inicia en función de la exigibilidad del derecho. En la ST 67/82, de 15 de noviembre, por la que se deniegan a las actoras, funcionarias del Mutualismo Laboral, las cotizaciones correspondientes al período de excedencia "voluntaria" a que se hubieron de someter con motivo de contraer matrimonio, en base a que las recurrentes, con motivo de promulgarse la Ley $56 / 61$, de 22 de julio, por la que declara la igualdad de la mujer respecto del hombre en el trabajo, habían conseguido la igualdad con anterioridad a la promulgación de la CE. Con ello, matiza el TC que el derecho que las recurrentes reclaman es el de «una supuesta discriminación actual derivada de una discriminación inicial efectiva, ulteriormente corregida". Puestos en la casuística de esta consideración, el TC debió considerar que en realidad las consecuencias de esta conducta seguian siendo discriminatorias respecto de los derechos fundamentales, y que fue con la CE con la que surge la posibilidad de accionar en amparo estos derechos, y no antes ni después.

Segunda.-Las oscilaciones en la interpretación del derecho a la igualdad.

El Tribunal Constitucional todavia no ha definido una línea clara de actuación en relación con la igualdad sexual. Las dos etapas sobre las que llama la atención FERNÁNDEZ-MIRANDA ${ }^{24}$, son además contrapuestas, es decir, que a partir de la sentencia 128/87, de 16 de julio, en la que se desestima la discriminación por plus de guardería a ATS masculino, se inicia una línea jurisprudencial completamente contraria a la que se venía manteniendo por parte del TC. Se aceptan las tesis del voto discrepante de Rubio Llorente en la sentencia 103/83, de 22 de noviembre, y se entra en el concepto de igualdad sexual que los constituyentes habian determinado.

El problema, como apunta Fernández-Miranda, queda sin embargo

24 M. C. Fernandez-Miranda, op. cit, pág. 129. 
planteado en cuanto a la indeterminación que presenta este cambio doctrinal y si se puede considerar que es el criterio definitivo o por el contrario cabe que el TC pueda cambiar nuevamente la orientación conforme a nuevas interpretaciones.

Tercera.-Que los efectos que ha tenido el primer período a que hacíamos referencia, restrictivos en cuanto a la prescripción, extensivos en cuanto a la igualación entre hombre y mujeres olvidando las circunstancias históricas subyacentes, han sido bastante disuasorios en cuanto al ejercicio de acciones derivadas de este derecho, en relación a otros derechos, como la tutela judicial o la libertad de expresión ${ }^{25}$. Por tanto, hay una conclusión general en cuanto a que la igualdad sexual hasta cierto punto no ha tenido el desarrollo jurisprudencial necesario en orden al cumplimiento de la igualdad pretendida en la Constitución.

25 Nótese, como formula Alonso OLEA, que la sensación que producen las primeras sentencias es precisamente la de una igualdad de los hombres respecto a los vestigios de proteccionismo en las mujeres, «mientras que la realidad era la muy otra situación de discriminación presente y extendida contra la mujer; con lo que el sentido de las normas antidiscriminatorias era la protección de ésta, de la mujer, para elevarla a un plano de igualdad real con el varón, con lo que resultaba estrábica la visión de la mujer privilegiada y el hombre oprimido", pág. 293, en «La acción afirmativa en cuanto a las condiciones de trabajo de la mujer». REDT, n. 30 , 1987. 


\section{BIBLIOGRAFIA}

Alonso Garcia, E.: “El principio de igualdad en el artículo 14 de la CE», Revista de la Administración Pública, 101, Madrid.

Alonso OleA, M.: «Sobre la "acción afirmativa" en cuanto a las condiciones de trabajo de la mujer», en Revista Española de Derecho del Trabajo, 30, 1987.

AtIEnZA, Manuel: «Sobre lo razonable en el Derecho», en REDC, 27, 1989.

BAÑo León, J. M.: "La igualdad como derecho público subjetivo», en Revista de la Administración pública, 114, 1987.

BARILE, Paolo: «L'eguaglianza e il pieno sviluppo della persona», en Diritti dell uomo e liberta fondamentali. Edt. II Mulino, 1984, Bologna.

Clavero, Bartolomé: “Cara oculta de la Constitución: sexo y trabajo», en Revista de las Cortes Generales.

Fernandez-Miranda Campoamor, Carmen: "La discriminación por razón de sexo. Algunos problemas derivados de una línea jurisprudencial vacilante», en $R e-$ vista de Derecho Político, 26, 1988, pág. 115-130.

Figueruelo Burrieza, Ángela: «lgualdad ante la ley, no discriminación por razón de sexo", en La Ley, 843, 1984.

JAÉn VALlejo, M.: «El principio de igualdad en la aplicación de la ley por los órganos jurisdiccionales en la jurisprudencia del TC», Rev. Colegio de Abogados, n. 2 , Madrid 1987.

Jiménez Campos, J.: “Igualdad jurídica como límite al legislador», REDC, 9, Madrid 1983.

Lasarte Álvarez, Javier: «La equiparación entre hombre y mujer en la Constitución», en La Ley, 648, 1983.

LEBEN, Charles: “Conseil Constitutionnel et le principe d'égalité devant la loi», Revue du droit public, 2, 1982.

LÓPEZ GonzAlez, José ignacio: El principio general de proporcionalidad en Derecho Administrativo, Universidad de Sevilla, 1988. 
LUCAS VERdú, Pablo: «El valor constitucional de la igualdad y la condición femenina», en Revista de Politica Comparada, 7, 1981-82.

Mellado López, Pilar, y Gómez Sanchez, Yolanda: «En torno a la posible inconstitucionalidad del apartado primero del artículo 57 de la Constitución Española de 1978». La Ley. Vol. 4. 1984.

ORtiz Lallana: «El principio de igualdad salarial y las discriminaciones indirectas por razón del sexo en el ordenamiento comunitario y en España", Revista Española de Derecho del Trabajo, 29, 1987.

Reposo, Antonio: «Igualdad constitucional y personas jurídicas», en Revista General de Legislación y Jurisprudencia, 255, 3, 1983.

Roca Trías, Encarna: «Principi d'igualtat i discriminacions per raó de sexe», en Revista Juridica de Cataluña, 2, 1988.

Rodriguez Piñero, Miguel, y Fernández Lopez, Maria Fernanda: Igualdad y discriminación, Editorial Tecnos, Madrid 1986.

Sanchez-URan Azaña, Yolanda: "Sobre el principio de igualdad y la insuficiente motivación del cambio de línea jurisprudencial», en Revista Española de Derecho del Tabajo, 34, 1988.

VALDÉS DE LA VEGA, Berta: "Sobre las discriminaciones por razón de sexo", en Revista Española de Derecho del Trabajo, 34, 1988.

— : «Valoración jurisprudencial en la jurisprudencia del Tribunal Constitucional», en Revista Española de Derecho del Trabajo, 1988.

AA.vV.: La mujer en el Derecho hispanoamericano. Instituto de la Mujer, Madrid 1983.

AA.vV.: Primeras jornadas de aplicación del derecho y la mujer. Instituto de la Mujer, Madrid 1984. 